\title{
Ciencia y recursos naturales a través del Periódico Oficial del Gobierno del Territorio de Quintana Roo, 1936-1940
}

\author{
Science and Natural Resources through the Official Gazette of the Government of the Territory of \\ Quintana Roo, 1936-1940 \\ Rodrigo Antonio Vega-y-Ortega-Báez
}

Resumen: Entre 1936 y 1940, Rafael E. Melgar gobernó el Territorio de Quintana Roo. En este lapso, se publicaron en el Periódico Oficial del Gobierno del Territorio de Quintana Roo varios escritos referentes a la explotación de la flora. El objetivo es comprender la valoración científica de los recursos vegetales de Quintana Roo en dicho periodo. La metodología retoma aspectos de la historia de la ciencia para demostrar algunos de los propósitos del gobierno de Melgar en torno a la exploración científica. En las conclusiones se destaca que el gobierno se interesó en elaborar el inventario botánico para modernizar la economía.

Palabras clave: ciencia, prensa, estudios ambientales, cardenismo, flora, política ambiental.

Abstract: During the governorship of Rafael E. Melgar between 1936 and 1940 in the Territory of Quintana Roo, several articles were published in the Official Gazette of the Government of the Territory of Quintana Roo, about the exploitation of tropical forests. The purpose of this article is to understand the scientific evaluation of botanical resources of Quintana Roo. The methodology is based on the History of Science to demonstrate some of the purposes of Melgar's government around scientificexploration. The conclusions argue that the government was interested in developing the botanical inventory to modernize the economy.

Keywords: science, press, environmental studies, cardenism, flora, environmental policy.

Rodrigo Antonio Vega y Ortega Báez. Doctor en Historia por la Universidad Nacional Autónoma de México. Profesor-investigador en el Instituto de Investigaciones sobre la Universidad y la Educación de la Universidad Nacional Autónoma de México. Temas de especialización: Historia de la ciencia mexicana/Historia ambiental de México. Correo electrónico: rodrigo.vegayortega@hotmail.com
Enviado a dictamen: 11 de mayo de 2016.

Aprobación: 7 de octubre de 2016.

Revisiones: 1 . 


\section{Introducción}

$\mathrm{E}$ 28 de septiembre de 1936 el general Lázaro Cárdenas del Río (1895-1970) dio a conocer la "Exposición del presidente de la República sobre la reconstrucción integral de los territorios de Baja California y Quintana Roo", como parte del fortalecimiento de su proyecto político-económico en dichas entidades del país que, a su juicio, estaban desarticuladas del resto de la nación, ya que:

Baja California y Quintana Roo han tenido que luchar contra el aislamiento que se deriva de su situación geográfica especial y de la falta casi absoluta de medios de comunicación hacia el resto de la República, para mantener con ésta la comunidad de la raza, la unidad de la cultura y las relaciones de índole económica que hacen de aquellas lejanas entidades parte integrante de nuestra nacionalidad [...] Despiertan lógicas ambiciones las inexploradas riquezas de los territorios, que por su extensión, por sus recursos forestales y mineros, por sus salinas, por la abundancia de su fauna acuática y terrestre y por la ventajosa topografía de sus litorales, constituyen zonas privilegiadas [...] El esfuerzo que el Ejecutivo se propone es [...] crear en ellos fuentes permanentes de producción, que ofrezcan base para el sostenimiento y la prosperidad de los pobladores (Cárdenas, 1978: 216).

Las palabras del mandatario son elocuentes en torno a la situación que había subsistido en los dos territorios federales del país desde el siglo XIX, en cuanto a la ausencia de una verdadera integración económica, social, política, cultural y territorial. La frágil situación de ambas entidades había sido aprovechada durante varias décadas por naciones "ambiciosas", a las que Cárdenas no hizo referencia explícita, pero es fácil suponer que se trataba de Estados Unidos y Gran Bretaña, no sólo por ser dos de las economías más importantes del mundo, sino porque México colindaba con ambos países. En particular, Quintana Roo se encontraba junto a Belice, una colonia británica de amplio peso geopolítico y económico. Esto hacía que dicho territorio se encontrara en la órbita imperial de Gran Bretaña, cuestión que se oponía a la ideología nacionalista del cardenismo.

Elpresidente mexicano también hizo referencia a las riquezas inexploradas - chicozapote, hule y maderas preciosas- del caso quintanarroense que, en lugar de formar parte de la unidad económica nacional, estaban explotadas por capitales extranjeros que nada tenían que ver con México. De ahí la importancia de llevar a cabo prospecciones científico-técnicas por parte del Estado mexicano para consolidar la "producción continua" en los municipios de Quintana Roo a partir del aprovechamiento de los recursos botánicos locales. Esta preocupación del presidente Cárdenas ya había sido compartida por otros mandatarios, al menos desde tiempos del general Porfirio Díaz.

La "Exposición..." de Cárdenas de 1936 retomó varios de los aspectos que el presidente observó en la visita que hizo a Quintana Roo durante la campaña presidencial de 1934. Una vez investido como presidente, el ll de enero de 1935, Cárdenas "hizo llegar al Congreso de la Unión la iniciativa de ley para restituir a Quintana Roo su calidad de Territorio Federal, expidiéndose el decreto correspondiente el 16 de enero del mismo año, volviéndose a reformar los artículos 43 y 45 de la Constitución de 1917" (Romero y Rioja, 2012: 6). El decreto reconfiguró los anteriores límites políticos y la extensión territorial. El Territorio se dividió en cuatro delegaciones: Chetumal, San Miguel Cozumel, Felipe Carrillo Puerto y Leona Vicario.

Ante este panorama político-económico, en esta investigación ${ }^{1}$ se propone comprender el papel de los recursos vegetales en la consolidación política del Territorio de Quintana Roo en el periodo 1936-1940, durante el mandato del general Rafael E. Melgar (18871959), quien gobernó por decisión del presidente Lázaro Cárdenas de febrero de 1935 a diciembre de 1940. Los años de gobierno de Melgar fueron definitorios para que el Territorio se consolidara como entidad política del país a pesar de los embates de Campeche y Yucatán por anexar sus ricos recursos naturales, además de las 
miras imperialistas británicas irradiadas desde Belice.

La fuente hemerográfica se compone de dieciocho escritos publicados en el Periódico Oficial del Gobierno del Territorio de Quintana Roo (POGTQR), que muestran algunos de los propósitos del gobierno de Melgar en torno a la exploración científica de la flora local. Tales escritos se encuentran agrupados en tres temas: fomento a la ciencia, aprovechamiento maderero y chiclero.

Esta investigación reconoce que "la construcción del concepto de ambiente abre una nueva perspectiva desde la cual es posible una reinterpretación de la historia de las relaciones sociedad-naturaleza" que requiere de la historia de la ciencia para abordar las vías teóricas y metodológicas en que dicho concepto se conformó en los siglos XIX y XX (Leff, 2005: 26). También cabe apuntar que cuando se desarrollan temas de historia ambiental se vislumbra que "la relación fundamental que subyace bajo todas las estructuras sociales es la existente entre los seres humanos y la naturaleza. De esta interacción básica proviene mucho de lo que los historiadores buscan entender: la economía, el derecho, lo político, el conflicto social y demás" (Worster, 2006: 25).

Hay que tener en cuenta que las "visiones de sociedades industrializadas de agricultura comercial a gran escala, de explotación desmedida de recursos" en muchas ocasiones se basaron en preceptos científicos que los gobiernos instrumentaron mediante políticas públicas (Rojas, 2010: 179). Así, los vínculos entre la historia de la ciencia y la perspectiva ambiental dan pie a visualizar el papel del conocimiento y la práctica científicas en el aprovechamiento de los recursos naturales y la transformación "en los ambientes físicos y biológicos y la forma como esos cambios afectan las sociedades humanas" (McNeill, 2005: 13).

Dichos vínculos se centran en la amplia cantidad de fuentes históricas provenientes de la ciencia que contribuyen a "la investigación ecohistórica en búsqueda de evidencia empírica para documentar cambios ambientales ocurridos en el pasado, pero también espera encontrar nuevos paradigmas interpretativos, conceptos y categorías analíticas" (Gallini, 2004: 151). La prensa oficial de los gobiernos deja ver las estrategias científicas que se implementaron como políticas públicas que incidieron en los ecosistemas en un periodo y un lugar determinados.

El período de Melgar es uno de los menos conocidos en la historiografía quintanarroense con respecto a otros momentos de la historia de Quintana Roo, por ejemplo los períodos de 1880 a 1934 y de 1960 a 1980. También es escasa la historiografía sobre el devenir de la ciencia en la entidad, aunque existen algunos trabajos de historia de la agricultura y la economía que se acercan a la cuestión científica. La presente investigación también se propone contribuir historiográficamente al conocimiento de dichos temas.

Como señala Carlos Macías, en Quintana Roo "la historiografía demoró en beneficiarse del tratamiento profesional, derivado del trabajo académico", por lo que los testimonios gubernamentales ocuparon "un espacio central en la consulta, el empleo y hasta la interpretación de la información histórica" (2007: 73). Sin embargo, se ha pasado por alto el aspecto de la ciencia quintanarroense, incluso en las fuentes de gobierno, como en el caso del POGTQR. ${ }^{2}$ Esto ha sido una característica de la historiografía quintanarroense "en cuanto a la alta influencia de temas políticoadministrativos, en demérito de los aspectos culturales, económicos y sociales" (Macías, 2007: 105).

El análisis del POGTQR deja ver que la publicación se erigió en el vocero del nuevo equipo político, en cuanto a fomentar el desarrollo económico regional basado en el aprovechamiento científico de los recursos naturales. La prospección de recursos era fundamental para legitimar la existencia del Territorio después del lapso inmediato anterior (1931-1934) en que fue anexado por los Estados de Yucatán y Campeche. La ausencia de recursos minerales, la carencia de industria y la lejanía del Territorio de los centros comerciales del país, hicieron que la extracción forestal se orientara a los mercados internacionales que demandaban materia prima, pero durante el cardenismo se llevó a cabo bajo la supervisión del Estado mexicano y no mediante los intereses privados, como sucedió en el siglo XIX. En el periódico se aprecia el interés del gobierno, las comunidades agrícolas y silvícolas, y los empresarios 
por el aprovechamiento de la flora regional, la cual requería de la Historia Natural y la Geografía para hacer posible su explotación racional, como sucedía en otras entidades, por ejemplo en Veracruz, Tabasco y Campeche.

\section{El contexto cardenista}

A partir de febrero de 1935, el presidente Lázaro Cárdenas elaboró el llamado Plan Pro-Territorios Federales que se hizo público con la "Exposición...” (Careaga, 1990: 205). Dicho plan retomó varios de los puntos nodales del informe de la Comisión Federal "Irigoyen", ${ }^{3}$ pues los argumentos científicos eran valorados por el gobierno cardenista como neutrales en las discusiones políticas, además de que se consideraban como directrices razonadas para construir el "progreso" mexicano.

La cuestión político-económica de Quintana Roo siempre estuvo presente en los proyectos de Cárdenas, e incluso antes de abandonar la presidencia visitó el Territorio en el lapso del 27 de noviembre al 7 de diciembre de 1939. Era la primera vez que acudía a ese lugar un presidente. La visita tuvo como propósito allanar la negociación para fijar los límites entre Yucatán, Campeche y Quintana Roo (Villarreal, 2009: 36). Meses después, el candidato a la presidencia, general Manuel Ávila Camacho, visitó Chetumal durante su gira en abril de 1940. Después de ser declarado presidente constitucional, Ávila Camacho propuso modificar en diciembre de 1941 la Ley Orgánica de los Territorios Federales, por lo que "se volvió a restablecer los límites entre Campeche y Quintana Roo de acuerdo al decreto de noviembre de 1902" (Romero y Rioja, 2012: 6). No obstante, la cuestión de los límites entre ambas entidades originó un conflicto por la jurisdicción de amplias zonas de maderas preciosas y chicozapote. Lo anterior sucedió durante la Segunda Guerra Mundial, pues "la producción chiclera volvió a aumentar, alcanzando niveles más altos que en 1929 y llevando al territorio a un nuevo auge económico", cuyo clímax fue en 1942 (Careaga, 1990: 215).

El gobernador Melgar recibió la encomienda de realizar "el reparto de tierras bajo el esquema ejidal propugnado por el gobierno federal llegando a establecer ejidos forestales en" las regiones norte, centro y sur (Villarreal, 2009: 35). El general Melgar de inmediato impulsó "obras de infraestructura, la reorganización de la producción forestal y agrícola, el reparto agrario y la transformación de las jornadas de trabajo" como medida tendiente a modernizar las bases productivas de la región (Careaga, 1990: 208).

El nuevo gobierno del Territorio buscó dar a conocer sus proyectos mediante el POGTVR. El carácter políticoadministrativo de la publicación hizo posible que llegara a todos los municipios del Territorio y que una amplia gama de lectores se interesara en adquirirlo de manera cotidiana, pues se relacionaba con aspectos económicos, sociales, educativos, políticos y demográficos. En atención al público, los redactores de forma constante publicaron la nota "Lee el Periódico Oficial" dirigida al "funcionario público, industrial, comerciante, cooperativista, obrero organizado y campesino ejidatario", es decir, a la heterogénea composición social de la población, pues en el POGTQR se darían a conocer las disposiciones legales que "afectaban sus intereses" (Redactores, 1938b: 4).

En el POGTQR también se dieron a conocer noticias del "progreso" material del Territorio, como la construcción del internado indígena y de numerosas escuelas, varias obras de dotación de agua, el saneamiento de drenaje y la pavimentación de calles en Payo Obispo, la inauguración de hospitales, muelles, campos de aviación y garitas de estaciones aduanales, además de la remodelación del palacio federal, la empacadora de mariscos y varios hoteles dirigidos al incipiente turismo regional ("Obras que se realizarán...”, 1936: 1). La diversidad de temas abordados en la publicación hace ver que prácticamente a todos los pobladores les interesaban los asuntos oficiales. Bastaba con que algún lector comentara o leyera en voz alta los textos de interés para la comunidad.

\section{Los recursos naturales de Quintana Roo}

El actual estado de Quintana Roo desde tiempos novohispanos estuvo sujeto a varias exploraciones 
científicas con miras a conocer sus recursos. En particular, después de 1821 algunos de los proyectos colonizadores, comerciales y silvícolas se vieron afectados por la llamada Guerra de Castas (1847-1901) que asoló la región. También el Estado mexicano tuvo varios obstáculos para afianzar la soberanía nacional frente a Guatemala y Gran Bretaña. Al respecto, hasta julio de 1893 se concretó la celebración del Tratado Mariscal-Saint John que estableció la frontera entre la República mexicana y las Honduras Británicas que delimitó in situ la Comisión de Límites encabezada por Antonio García Cubas (Cisneros, 2014: 41). Una vez erigido en 1902 el Territorio de Quintana Roo, "el gobierno federal incrementó su control y jurisdicción territorial a través de las autoridades militares y por medio de los concesionarios particulares que actuaron como 'marcadores de soberanía' en términos políticoeconómicos" (Rangel, 2013: 4).

La flora quintanarroense se insertó en "los ciclos económicos de la demanda mundial de las materias primas forestales, como la caoba, el cedro y el palo de tinte" que, en general, se exportaban a Europa occidentaly, después de la segunda mitad del siglo XIX, también a Estados Unidos (Villalobos, 2006: 54). El chicozapote, el hule y las maderas finas "satisfacieron [sic] las necesidades de los centros industriales textiles, la construcción de flotas navales mercantes y militares, la ebanistería, la expansión de los ferrocarriles con la manufactura de durmientes o la elaboración de goma de mascar" (Rangel, 2014: 381). Esta explotación silvícola se intensificó en el último tercio del siglo XIX, para llegar al zenit un siglo después, no sin antes padecer distintas depresiones en la exportación.

Las regiones naturales de Quintana Roo, a grandes rasgos, se pueden dividir en selva, sabana o manglar y costa. En la selva se encuentran las especies maderables, el chicozapote (Manilkara zapota), además de las comestibles y las medicinales; en la sabana habita el palo de tinte (Haematoxylon campechanum), y en la costa abunda la pesca. En relación con lo anterior, las zonas económicas son: norte (pesca, silvicultura y chicle), centro (agricultura, chicle, hule y maderas) y sur (pesca, ganadería, agricultura y comercio) (Careaga, 1990: 27).
Las tres zonas se integraron al proyecto cardenista durante la gubernatura de Melgar.

De acuerdo con la Comisión Nacional para el Conocimiento y Uso de la Biodiversidad, en dichas regiones naturales de Quintana Roo "la riqueza florística se calcula en 1,800 especies”, con un 10\% de las 18000 especies de flora nacional. "Se calcula que 150 familias de plantas vasculares se encuentran representadas en la vegetación de Quintana Roo" (Valdez-Hernández e Islebe, 2011: 32). Esto muestra que dicha entidad política goza de una amplia biodiversidad vegetal, a pesar de que ésta ha sufrido distintas explotaciones en los últimos siglos.

Durante la presidencia de Cárdenas, la política económica se desarrolló a partir de seis objetivos generales:

1) nacionalismo o economía propia, autónoma, dirigida y actuada por mexicanos; 2) colonización o conquista para la agricultura de las tierras ociosas; 3) industrialización o revolución industrial como la que había hecho ricos y poderosos a los países que lo eran; 4) sustitución de la economía de autoconsumo por la economía de compraventa, y comercio exterior limitado a la compra de maquinaria y equipos de trabajo y a la venta de manufacturas, y sólo transitoriamente a la de materias primas; 5) subida de jornales; y 6) intervención del Estado en todas las ramas y en cada uno de los instantes de la vida económica (González y González, 1997: 67).

En cada uno de los objetivos señalados estuvo presente la ciencia y la tecnología, dependiendo de sus áreas de injerencia. Para el caso de Quintana Roo, la práctica científica dejó su impronta en el nacionalismo pues, a la par que durante el cardenismo, se apoyó una estrategia de economía autónoma, semejante al contexto de las ciencias, ya que se dotó de amplios recursos a las instituciones educativas para generar nuevos cuadros científico-técnicos que se destinarían a explotar los recursos de cada región. Lo mismo puede decirse de la agricultura, ya que la "conquista" de las tierras ociosas sólo sería posible mediante las directrices de 
la Botánica, la Agronomía y la Geografía, pues de lo contrario esa "conquista" quedaría en manos de la rutina y la costumbre de los campesinos considerados como ignorantes y atrasados. Por último, es palpable que el Estado mexicano valoró la ciencia como un brazo "racional" del Estado con el cual los gobernantes de distintos niveles podrían tomar las mejores decisiones para el futuro del país, sobre todo en el rubro del aprovechamiento de los recursos naturales.

Durante el cardenismo se intensificó el proyecto ejidal al poner en vigor el Código Agrario (1934) que "creó una estructura administrativa jerárquica y asimétrica, donde el presidente de la República centralizaba la autoridad agraria, ejerciéndola" mediante el Departamento Agrario y el Cuerpo Consultivo Agrario. Ambos se encargaban de "dictaminar los expedientes y cuyos miembros eran nombrados por el presidente, lo que a su vez le restaba funciones rotatorias a los gobernadores" (Escobar y Sandre, 2009: 204). Durante el gobierno de Melgar se constituyeron 32 ejidos entre 1936 y 1940. Varios de ellos provinieron de las ex haciendas de El Cuyo y de Santa María (Villarreal, 2009: 131). El Gobierno federal consideró importante modernizar la agricultura a través de bases científicas al poner a disposición de los ejidatarios distintos "métodos modernos de cultivo, semillas selectas, fertilizantes y máquinas [...] Las autoridades se volverían las tutoras de la flora y la fauna" al desarrollar un plan de vigilancia para prevenir la tala inmoderada, emprender trabajos de reforestación y aprovechar "los bosques de manera racional y económica", como se proyectó en el plan sexenal 1935-1940 (González y González, 1997: 147).

\section{El fomento a la ciencia}

Durante la primera mitad del siglo XX, en Quintana Roo se desarrollaron varias actividades científicas de diferente tipo, algunas impulsadas por el Gobierno federal y otras por los gobiernos regionales. Durante el cardenismo se llevó a cabo la Expedición Científica Mexicana (1937), a cargo de Luis Rosado Vega (literato yucateco), que fue patrocinada por la Secretaría de Educación y la Secretaría de Comunicaciones para conocer los recursos del Territorio de Quintana Roo e integrarlos a la economía nacional. La expedición escudriñó éste desde la óptica de la Historia Natural, la Geografía, la Medicina, la Meteorología y la Topografía, por lo que se requirió del acopio de científicos y de los objetos que requerían para cumplir sus objetivos. La expedición presentó un informe que evidenció aspectos poco conocidos de la región, en términos de la naturaleza y el territorio.

El informe sentó las bases para la elaboración de un plan político-económico para Quintana Roo que se desarrolló durante el cardenismo. El 16 de agosto de 1936 en el POGTQ se publicaron las "Bases a que deberá sujetarse en su funcionamiento el Comité creado para la vigilancia, explotación y exportación del chicle, maderas y demás riquezas forestales en los Estados de Veracruz, Campeche, Tabasco, Chiapas y Yucatán y en el Territorio de Quintana Roo", por parte de Rafael Sánchez Tapia (secretario de la Economía Nacional), Eduardo Suárez (secretario de Hacienda y Crédito Público) y Miguel Ángel de Quevedo (jefe del Departamento Forestal y de Caza y Pesca). Estas bases económicas fueron parte del acuerdo presidencial del ll de agosto de ese año para regular, a partir de bases científicas, la silvicultura, que era una de los ramos económicos de mayor peso en dichos estados que carecían de minas e industria (Sánchez Tapia, Suárez y De Quevedo, 1936: 1). Las "Bases..." estuvieron relacionadas con el "Programa de trabajo que desarrollará el Gobierno de la República en los Territorios Federales de la Baja California y Quintana Roo" del 1 de octubre de ese año, fecha en que el presidente Lázaro Cárdenas dio a conocer los acuerdos para "la acción conjunta" que desarrollarían la Secretaría de Agricultura y Fomento, la Secretaría de Economía Nacional, y la Secretaría de Comunicaciones y Obras Públicas (Cárdenas, 1936:3). Como se aprecia, Cárdenas no escatimó fondos para desarrollar las estrategias más eficientes destinadas a la explotación de los recursos de Quintana Roo, para lo cual se reunió el capital humano de las secretarías de estado en que laboraban ingenieros, médicos, farmacéuticos, naturalistas, veterinarios y profesores normalistas. 
En términos de la estructura gubernamental de Quintana Roo, en el POGTQR se publicó en varias ocasiones el "Directorio. Funcionarios públicos del Territorio y de la Federación. Oficinas”, que incluyó datos del personal de: la Delegación Forestal y de Caza y Pesca (Alfonso Pulido Mora), el Departamento Agrario (ingeniero Luis Briones Moreno), la Delegación Sanitaria (médico Atenógenes Heredia) (Redacción, 1937: 10), la Dirección de la Secretaría de Educación Pública (profesor Leopoldo Aguilar Roca), la Delegación del Departamento Forestal y de Caza y Pesca (ingeniero Raymundo E. Enríquez), ${ }^{4}$ la Delegación del Departamento Agrario (ingeniero José Villaseñor), y la Delegación del Departamento de Salubridad Pública (médico Jaime López Mijares) (Redactores, 1938a: 4). Aunque en el "Directorio..." sólo figuran los jefes de cada sección, es palpable la conformación paulatina de un entramado científico al servicio del gobierno regional, que en un principio fue reducido, pero con el tiempo creció en relación con los objetivos federales: explotación silvícola, defensa de la soberanía territorial y aumento demográfico.

Los gobiernos federal y regional destinaron recursos a la formación científica de la población en distintos niveles educativos. Por ejemplo, en julio de 1936 se otorgaron "pensiones a jóvenes para inscribirse en las escuelas politécnicas de agricultura y medicina en el D.F. y en la regional campesina de Hecelchekán, Yucatán" (Careaga, 1990: 209). Con esta medida, el gobierno de Melgar esperaba que, al concluir los estudios, los alumnos pensionados regresarían a Quintana Roo para incorporarse a la administración pública, las cooperativas o las empresas privadas.

En términos de la educación pública también en dicho mes se publicó en el POGTQR que la Secretaría de Educación Pública había aprobado la fundación de la Escuela Secundaria "Quintana Roo" en Chetumal. El plan de estudios se conformó de asignaturas como Castellano, Matemáticas, Geografía (a cargo del licenciado Juan Requena Repetto), Biología y Botánica (por el médico Atenógenes Heredia), Inglés, Dibujo y Modelado (por el ingeniero Carlos Alvarado), Escritura, Música y Orfeones, Cultura Física, Prácticas Agrícolas y
Forestales (por el ingeniero Manuel Medina), y Prácticas de Taller, Labores Femeniles y Civismo (Aguilar, 1936a: 3). El director de la escuela fue el licenciado Enrique Fernández del Campo y el secretario fue Leopoldo Aguilar Roca. Como se advierte, la enseñanza científica buscó la incorporación de los estudiantes a la práctica de la ciencia a través del desempeño docente de algunos de los miembros de la administración de Melgar.

Leopoldo Aguilar Roca publicó el "Plan General de trabajo de las escuelas federales del Territorio de Quintana Roo, para desarrollar durante el año escolar de 1936-1937", que anunciaba la puesta en marcha de la educación socialista bajo el postulado de que "el trabajo productivo y socialmente útil" resolvía problemas económicos, políticos y sociales. En cuanto a lo económico, Aguilar Roca reconocía que "las principales fuentes de producción que [constituían] la economía del Territorio de Quintana Roo, [eran] la explotación de la resina del chicozapote (chicle) y el corte de caoba" (Aguilar, 1936b: 5). Bajo este panorama productivo, la escuela socialista se proponía facilitar a niños y adultos conocimientos científicos y tecnológicos que, "basados en el trabajo productivo y socialmente útil, los [capacitara] para dirigir la economía del propio Territorio e incorporar a la economía nacional" conforme a la reforma del artículo tercero constitucional (Aguilar, 1936b: 6). A pesar del cambio ideológico en la educación pública, la ciencia se mantuvo presente en la reforma educativa, pues era valorada como el elemento útil, práctico y racional que auxiliaría a los mexicanos a mejorar el aprovechamiento de los recursos naturales.

G. Vázquez Vela dio a conocer el 2 de enero de 1937 la convocatoria del "Concurso de la mejor escuela rural", en que un jurado calificador tomaría en cuenta los siguientes puntos: el aprovechamiento de los anexos de granja (campo de cultivo y de experimentación agrícola, huerto escolar, gallineros, apiario, porqueriza y palomar), los talleres (carpintería, curtiduría, pequeñas industrias), los aspectos docentes en pruebas de Geografía e Historia (mapas, gráficas y cuestionarios) y de ciencias naturales (plantas útiles de la región, cultivos, plagas y manera de combatirlas), y la acción agrícola (mejoramiento de los procedimientos de 
cultivo empleados en la región) (Vázquez, 1937: 3). Los elementos que se juzgarían eran comunes en las escuelas rurales, pues su objetivo era dotar a los alumnos de los elementos científicos, teóricos y prácticos, para que éstos al egresar pudieran incorporarse a la fuerza laboral o continuar sus estudios en el ámbito científico en beneficio de Quintana Roo.

\section{Las maderas}

La explotación de caoba, cedro y palo de tinte en Quintana Roo creció de manera continua durante la primera mitad del siglo XX. Desde 1902, estas especies vegetales se exportaban a Francia, Gran Bretaña, Alemania y Estados Unidos. Lo anterior inició en la década de 1890, cuando "estos productos representaban entre el 4 y $6 \%$ de las exportaciones nacionales, y lograron mantener tal proporción hasta principios del siglo XX", gracias a los empresarios madereros extranjeros y mexicanos (Villalobos, 1993: 88). Dos de las propiedades privadas de mayor extensión fueron las mencionadas Compañía Colonizadora de la Costa Oriental de Yucatán, S.A. (1896) y la Compañía Agrícola del Cuyo y Anexas, S.A. (1897), que fueron expropiadas en la década de 1930 para llevar a cabo el reparto agrario a través de la Compañía Comercial de Fincas Rústicas y Urbanas, S.A., del Banco Nacional de México, que fue propietaria de 2627 kilómetros cuadrados de tierras en Quintana Roo (Rangel, 2013: 20).

Una de las primeras acciones del gobierno de Melgar se reprodujo en el POGTQR el 1 de febrero de 1936, al reseñar la entrega del aserradero privado a la Cooperativa de "Ejidatarios de Chetumal". El aserradero se encontraba en Chetumal y constituyó un acto político que convocó a trabajadores, funcionarios y empleados federales para hacer la entrega formal a la Sociedad Cooperativa Limitada como uno de los logros económicos y sociales del gobierno de Melgar. La dotación se conformaba del local, un tren de aserradero con maquinaria para cepillar, machimbrar maderas y hacer tejamaniles, talleres de ebanistería y carpintería tractores, trucks y bancos de carpintería. Con ello, Melgar confiaba en que los ejidatarios formarían la cooperativa, "en la inteligencia de que la misma [contaría] además con la casa de mampostería y palma en que se encuentra ubicada, con una reserva forestal para la explotación de maderas con superficie aproximada de 8825 hectáreas debidamente monteadas" con el permiso correspondiente de la Delegación Forestal de Caza y Pesca. El gobierno de Quintana Roo pagó 6000 pesos como primer abono a los antiguos dueños (Melgar, 1936a: 1). Este acto fue aprovechado por Melgar para mandar un mensaje político acerca de la importancia de que los medios tecnológicos de la silvicultura fueran públicos para asegurar la riqueza de Quintana Roo, a la vez que mandó una señal a la sociedad sobre la importancia de las cooperativas para desarrollar la economía regional.

En varios números del POGTQR se dieron a conocer las resoluciones sobre entrega definitiva de tierras a los pueblos, como parte de la estrategia de Melgar para arraigar a la población trashumante que dependía de la explotación forestal y para dotar de ejidos a las comunidades. En el caso del pueblo de Kantunilkín, Delegación de Cozumel, la Comisión Local Agraria llevó a cabo el censo agropecuario y recabó los datos técnicos señalados en la Ley Agraria. La Comisión también pidió a un ingeniero que determinara la extensión de los terrenos propiedad de la nación, para indicar la dotación ejidal (Zepeda, 1936b: 3). El dictamen del Departamento Agrario expresó que "siendo de utilidad pública la conservación y propagación de los bosques y arbolados en todo el territorio nacional, [debía] apercibirse a la comunidad beneficiada con esta dotación, que [quedaban] obligados a conservar, restaurar y propagar los bosques y arbolados" de la superficie dotada (Zepeda, 1936b: 3). La mayoría de las dotaciones de ejidos mantuvo este proceso administrativo. Con respecto a la ciencia, casi siempre se involucró a los actores científicos del gobierno, en especial los ingenieros, quienes estaban capacitados en la práctica geográfica y topográfica para determinar la extensión exacta de los nuevos ejidos y, posteriormente, efectuar un croquis en que se asentara el perímetro de éstos. También resalta el aspecto naturalista, mediante la presencia de la Delegación Forestal de Caza y Pesca, 
para asegurar que la explotación silvícola sería eficiente en términos científico-técnicos, dejando de lado la tradición empírica practicada por los indígenas mayas, valorada de ineficaz por la roza.

También fue recurrente la publicación de las cédulas notificatorias comunes a los propietarios de fincas afectables conforme al Código Agrario, situadas en un radio de siete kilómetros de los poblados, como el de Kantunilkín. De nuevo una comisión, que incluyó practicantes de la ciencia, elaboró el censo general y agrario del pueblo, tras lo cual se notificó a los propietarios de los predios afectables que disponían de quince días para darse por enterados. Después, los dueños nombrarían "su representante común que deberá intervenir en la formación del censo" (González Ramírez, 1937: 4). Aunque no es posible conocer con exactitud la composición de la comisión que conformaría el censo, es de suponer que, al menos el gobierno, enviaría a ingenieros para tomar los datos necesarios y emitir un dictamen científico sobre el asunto.

En el POGTQR se publicaron todas las resoluciones de los expedientes de dotación de ejidos a los poblados de Quintana Roo por parte del presidente Lázaro Cárdenas, como el caso de Chuiquilá, Delegación de Isla Mujeres. Las resoluciones primero se daban a conocer en el Diario Oficial y luego en el POGT2R. La resolución sobre Chuiquilá prohibió a los pobladores la tala en el área boscosa declarada parque nacional o reserva forestal, "en las cuales podrán aprovechar madera muerta, pastos y esquilmo que no impliquen su perjuicio o destrucción" (Cárdenas, 1939b: 8). El brazo del Ejecutivo encargado de velar por la protección de los bosques sería el Departamento Forestal. Aunque no todas las resoluciones ejidales implicaron la protección de las selvas, el Departamento fue un actor destacado en el aprovechamiento silvícola mediante criterios científico-técnicos.

El 15 de diciembre de 1940 el gobernador Melgar dio a conocer la "Resolución de ejidos del poblado de Allende — antes Estévez-, Río Hondo, Delegación de Ciudad Chetumal, Territorio de Quintana Roo". En ésta, los comisionados describieron varios aspectos del territorio; probablemente fueron ingenieros, pues se detalló que el derrotero que comunicaba Allende y Chetumal se recorría mediante canoas de motor y cayucos. También se señaló que el clima era cálido y las lluvias abundantes, "siendo los principales cultivos del lugar el maíz y frijol en muy pequeña escala”. Los supuestos ingenieros observaron que las selvas producían "maderas de diferentes especies, tanto de construcción como preciosas y que los únicos terrenos afectables para la dotación de que se trata [eran] los nacionales" (Melgar, 1940: 1). La resolución de dotación de ejidos en casi todas las ocasiones incluyó algunos párrafos relacionados con el territorio sobre el cual se llevaría a cabo el deslinde, tanto en las características climáticas, para recomendar el tipo de actividad, como en la hidrografía, que representaba la vía de comunicación al interior del Territorio. Los ingenieros fueron los practicantes de la ciencia capacitados para desarrollar este tipo de apreciaciones técnicas con las cuales se basaba la resolución presidencial.

\section{El chicle}

La resina del chicozapote, conocida como chicle, fue uno de los rubros económicos de mayor importancia en Quintana Roo desde finales del siglo XIX hasta mediados del XX (Pérez, 2014: 199). En la historiografía hay un consenso acerca de que en 1880, al norte del Territorio, inició la explotación del chicle mediante la Compañía de la Costa Oriental y El Cuyo y Anexas. Hasta 1915 inició el aprovechamiento sistematizado en las zonas sur y centro (Pérez, 2014: 199).

En el POGTQR se publicaron numerosas actas de posesión provisional de los poblados que solicitaban ejidos para explotar el chicozapote, como la del 16 de abril de 1936 a nombre de los pobladores de Solferino, Delegación de Isla Mujeres. En este caso, Manuel C. Junco, secretario de Gobierno y delegado del Departamento Agrario, explicó a la comunidad las ventajas "que se obtienen con la dotación, la forma en que se [habría] de trabajar en los montes concedidos y todo aquello que estimó de interés para la comunidad y enseguida el ingeniero Solórzano dio lectura a la 
sentencia mencionada" (Zepeda, 1936a: 1). Al pueblo se le otorgó un total de 18440 hectáreas, para lo cual el gobierno pidió la constitución de una cooperativa de los campesinos:

[...] quedando sujetos a las disposiciones dadas o que en lo sucesivo dieren el gobierno del Territorio y el Departamento Autónomo Forestal y de Caza y Pesca en lo relativo a la explotación de otras especies comprendidas dentro de los terrenos entregados, quedando igualmente obligados a la conservación de los montes para la explotación de la resina del chicozapote, dividiendo la superficie entregada en cinco porciones que serán explotadas paulatinamente durante cinco años, tiempo indispensable para que los árboles picados el primer año recobren su vitalidad y puedan serlo al finalizar el quinto y así sucesivamente, para lo cual la Comisión Agraria Mixta y la Delegación Forestal dictarán las medidas que juzguen pertinentes [...] Se hizo saber a los beneficiados que ya se enviaría el personal de ingenieros necesario para efectuar los deslindes (Zepeda, 1936a: 1).

La resolución planteó la participación continua de los ingenieros como actores de la ciencia contratados por el Estado mexicano en sus distintas dependencias. También es claro que el Departamento Forestal y de Caza y Pesca fue la instancia científica que regularía los procesos de explotación en varios ejidos quintanarroenses, además de la protección de algunas áreas selváticas. El Estado mexicano destinó recursos para la puesta en marcha de un plan racional de explotación silvícola que contrastaba con las actividades tradicionales, consideradas por éste como poco eficientes para el aprovechamiento del recurso vegetal. Por ello, el Departamento Forestal fungía como preceptor de los chicleros mayas.

Las resoluciones presidenciales relativas a la dotación definitiva de los ejidos de cada pueblo, en general señalaron los usos económicos. En el caso del pueblo de Sac-Xán, Delegación de Payo Obispo, el 1 de junio de 1936 se estableció "que los medios de vida del poblado [eran] la industria del chicle, pues que la agricultura [era] tan raquítica que el poquísimo maíz y frijol que se producen [eran] apenas suficientes para satisfacer las necesidades de los campesinos" (Zepeda, 1936a: 1). También se detalló el clima cálido, la gama de especies vegetales - chicozapote, caoba, yuca, plátano, caña de azúcar y frutales-, que el terreno era plano y cubierto por bosques "en su mayor parte explotados", cuya veda era por diez años, y las tierras eran de mala calidad "dado el poco espesor de su capa arable" (Zepeda, 1936a: 1). Los ingenieros efectuaron dicha caracterización, tanto la territorial como la natural, pues de ella dependía si el ejido se destinaría a la producción de chicle, la agricultura o el corte de maderas.

Las solicitudes de tierras de los vecinos en general tuvieron la misma estructura discursiva, como el caso de Nocbec, Delegación de Payo Obispo, publicada el 16 de julio de 1936. En ésta, el Comité Particular Ejecutivo de este pueblo se dirigió al gobernador para exponer que los habitantes vivían exclusivamente "de la explotación de chicle, industria para la que se [requería] disponer del monte indispensable para la misma", el cual los contratistas particulares explotaban, viéndose obligados a "trabajar con ellos y a venderles productos a veces a bajísimos precios y siempre de acuerdo con la mejor conveniencia de ellos" (García, 1936: 3). El 30 de noviembre del mismo año, Rafael E. Melgar publicó en el POGTQR la "Dotación de tierras al poblado de Nohbec. Resolución”, después de que la Comisión Agraria Mixta emprendió el censo general y agropecuario a cargo del ingeniero auxiliar Enrique García S. De los datos técnicos del censo, "se dedujo que dentro del radio legal de 7 kilómetros alrededor del núcleo gestor únicamente se [encontraban] terrenos nacionales afectables", por lo que se otorgó al poblado la cantidad de 18840 hectáreas (Melgar, 1936b: 3). La presencia de los ingenieros para la conformación de los censos, la interpretación de los datos técnicos - naturales, geográficos, legales y demográficos-, la elaboración de los croquis y mapas, y la asesoría para los dictámenes gubernamentales, fueron imprescindibles en la reforma agraria cardenista en Quintana Roo, y en el resto de México.

El censo elaborado por el ingeniero García S. mostró que la comunidad no carecía de tierras de cultivo, sino 
de montes explotables que garantizaran "su bienestar económico y por consiguiente su adaptación al ambiente de vida nacional", cuestión vital para el plan político-económico de Cárdenas y Melgar. De nuevo, el ingeniero analizó el clima y el régimen de lluvias, siendo la precipitación máxima de 1200 milímetros, “y el tiempo de lluvias único apropiado para extracción de la resina del chicozapote" (Melgar, 1936b: 3). La vegetación se componía de maderas preciosas (caoba, cedro, brazilete y guayacán), maderas industriales (chicozapote) y de construcción (machiche, ciricote, quebracho, ramón y jabín). Mientras que la vegetación "herbácea [era] abundante y variada, encontrándose gran número de plantas medicinales" (Melgar, 1936b: 3). La caracterización de la flora, en términos útiles a la economía, fue común en las resoluciones de dotación de tierra a cada poblado. Esto era necesario para dar a los pobladores el medio de sustento económico basado en la naturaleza local. El ingeniero y otros practicantes de la Botánica, como los médicos, aportaban los datos técnicos vegetales para su aprovechamiento, pues, en algunos casos, los habitantes pasaban por alto ciertas especies que representarían de ahora en adelante una actividad complementaria a la tradicional.

En cuanto al suelo, el ingeniero García S. determinó que la calidad era mala, como en el resto del Territorio, "pudiendo considerarse como de temporal de segunda, existiendo no obstante porciones de terrenos en que la capacidad arable [era] superior a 45 centímetros de espesor". El suelo estaba formado por humus y arcilla, en que se sembraba maíz y frijol en milpas, después del desmonte y la quema de las plantas "inútiles" (Melgar, 1936b: 4). Los análisis edafológicos representaban una evidencia científica para evaluar la capacidad de las tierras que se adjudicarían a cada pueblo. Como en la mayoría de los poblados, el suelo era impropio para la agricultura intensiva, y casi todas las dotaciones agrarias seinscribieron en los rubros de corte de maderas preciosas o producción chiclera. El conocimiento empírico de los habitantes fue sancionado por los peritajes científicos dentro de la clasificación edafológica.

El 16 de agosto de 1937, Melgar expresó, en la resolución sobre la reserva forestal para el poblado de Tulum, Delegación de Cozumel, que después de que los ingenieros terminaran los "ensayos necesarios para saber el promedio de árboles explotables que [había] por hectárea", se llegó a la conclusión de que en esa zona había un promedio de once árboles, cuyo diámetro oscilaba entre 65 centímetros y un metro, y la producción media por árbol era de 1.5 kilos de resina. Con base en varios cálculos, los ingenieros determinaron que de una hectárea se obtenían 16 500 kilos de resina, y que para obtener 690 kilos se requerían 42 hectáreas "por individuo, siempre y cuando esa superficie estuviera totalmente cubierta de zapotes". No obstante, se calculó que sólo el 50\% de cada hectárea era explotable, por lo que debía aumentarse la parcela hasta 48 hectáreas por individuo, pero como la explotación de chicle se efectuaba en un ciclo de cinco años, habría que dar a cada individuo 420 hectáreas (Melgar, 1937: 9). Los cálculos realizados por los ingenieros a partir de los datos técnicos acopiados en los censos proporcionaban al Estado la directriz para determinar la extensión de los ejidos para las cooperativas chicleras sin que mediaran en el POGTQR, en apariencia, preferencias políticas, sino la supuesta certidumbre de los informes científicos.

El 30 de noviembre de 1939, el presidente Cárdenas dio a conocer el "Acuerdo que prohíbe el otorgamiento de permisos para la explotación de chicle en la región de Los Chenes del Estado de Campeche y Territorio de Quintana Roo". En este acuerdo se señaló que, después de que la Cooperativa Productores de Chicle "Los Chenes" obtuvo resultados satisfactorios en la explotación del chicle, el Departamento Forestal y de Caza y Pesca no otorgaría permiso de explotación de chicle en terrenos nacionales a particulares en dicha región, pues se requería la regeneración de los chicozapotes para que en el futuro se asegurara su aprovechamiento (Cárdenas, 1939a: 2). La disposición proteccionista del Departamento se basó en un estudio que varios ingenieros llevaron a cabo en Los Chenes por varias semanas. El interés del Departamento era fomentar el aprovechamiento racional que mantuviera en buenas condiciones la región y sirviera de ejemplo para otros predios nacionales. 


\section{Consideraciones finales}

Cabe indicar que esta investigación forma parte de un estudio más amplio sobre el desarrollo científico-técnico en Quintana Rooen el siglo XX que se complementarácon el análisis de otras fuentes archivísticas, bibliográficas y hemerográficas que den cuenta de la gama de actores, objetivos y resultados que estuvieron en marcha en dicha región.

Las historias de la ciencia y del ambiente aún son áreas de estudio en construcción a pesar de los numerosos trabajos de investigación que se han desarrollado en las últimas décadas, como se aprecia en el caso de la ciencia quintanarroense. ${ }^{5}$ Ambas historiografías, en el caso de Quintana Roo, han pasado por alto el devenir del conocimiento científico en sus múltiples expresiones y los diversos actores que la hicieron posible por el aprovechamiento de la flora.

En el caso de los estudios sobre el cardenismo, también son escasos los trabajos sobre la promoción de la ciencia, ya que sólo se ha enfatizado el desarrollo de las instituciones de la Ciudad de México, dejando de lado a otras ciudades y regiones. Aunque en la historiografía se menciona de forma continua el interés del grupo cardenista por la ciencia y la tecnología, se valoran éstas como elementos secundarios para estudios de corte económico, social, político, educativo o internacional.

La hemerografía es una fuente valiosa para comprender los vínculos entre la ciencia y la transformación ambiental a través de un proyecto político-económico, como los desarrollados después de la Revolución mexicana. El caso de la prensa gubernamental, de la que forman parte, por ejemplo, los numerosos periódicos oficiales de cada estado y territorio del país, permite ver las iniciativas que se pusieron en práctica desde el ámbito gubernamental para modernizar el aprovechamiento de los recursos naturales mediante la ciencia. El gobierno aportaría los elementos racionales para enseñar a los agricultores, silvicultores, ganaderos, artesanos, rancheros y hacendados a hacer más eficiente la explotación del recurso que tenían a su disposición.
En el caso de Quintana Roo, los recursos vegetales constituyeron la fuente económica de la región desde tiempos coloniales hasta el despegue del turismo en la segunda mitad del siglo XX. La inserción comercial de las especies quintanarroenses en el contexto internacional explica los intereses de las élites de Campeche y Yucatán por controlar la región, así como los motivos de los gobiernos federales que, a pesar de la lejanía, procuraban controlar la riqueza natural del Territorio en detrimento de los otros estados peninsulares.

De ahí que los actores científicos hayan estado presentes como practicantes de la Historia Natural y la Geografía, además de la Meteorología, la Topografía, la Climatología y la Medicina, por varios siglos. Del último tercio del siglo XIX en adelante es evidente que los ingenieros destacaron por su actividad científica dirigida a ocupar el entramado burocrático que reclamaba especialistas para determinar las características naturales, territoriales y climáticas de Quintana Roo, además de para la delimitación de fronteras con Campeche, Yucatán y Belice. Desde este último territorio, el gobierno británico se apropió de manera ilegal de los recursos vegetales mexicanos, razón por la cual el gobierno cardenista se interesó en elaborar el inventario botánico del Territorio, el mapa y el censo oficiales, y la delimitación topográfica.

Mientras el gobernador Melgar ponía en práctica el proyecto cardenista de modernizar la explotación vegetal en Quintana Roo, también desarrolló una estrategia educativa orientada a la formación de nuevas generaciones de científicos, tanto profesionales como amateurs, a través de las asignaturas científicas, en particular botánico-agronómicas, en distintas escuelas del Territorio. Además, se fomentó la instrucción naturalista al organizar concursos entre las escuelas para demostrar la valía de la ciencia en el futuro de la sociedad.

Si bien el Departamento Forestal y de Caza y Pesca se originó antes del gobierno de Cárdenas, fue la instancia ambiental del Poder Ejecutivo para desarrollar varias políticas públicas en torno al aprovechamiento de los recursos naturales mediante directrices científicas bajo el gremio de los ingenieros. Este Departamento participó en la dotación de ejidos en Quintana Roo y el 
resto del país, para asegurarse de que las comunidades beneficiadas hicieran buen uso de los elementos ambientales que tenían a su disposición.

\section{Notas}

1 Esta investigación es parte del proyecto PAPIIT núm. IN 302416: "Las investigaciones geográficas y naturalistas en México (1786-1950)". Responsable: Dra. Luz Fernanda Azuela, del Instituto de Geografía de la Universidad Nacional Autónoma de México. También es parte del proyecto PIFFYL (2015-032): "Historia ambiental iberoamericana (siglos XIX y XX): propuestas historiográficas y metodológicas". Responsable: Dr. Rodrigo Vega y Ortega, Facultad de Filosofía y Letras de la Universidad Nacional Autónoma de México.

${ }^{2}$ Otra investigación sobre periódicos oficiales de los estados del país como fuente para la historia de la ciencia y la historia ambiental se encuentra en Vega y Ortega (2015: 163-194).

${ }^{3}$ Ulises Irigoyen, oficial mayor de la Secretaría de Hacienda y Crédito Público, fue designado jefe de la comisión científica. Éste publicó un informe con el título de El problema económico de Quintana Roo: estudio de la Comisión Federal que fué designada para llevar a cabo una jira por aquella región y proponer las medidas adecuadas para su desarrollo económico y su vinculación política y administrativa con el resto del país (1934).

${ }^{4}$ El ingeniero Enríquez fue gobernador de Chiapas en el periodo 1928-1929, postulado por el Partido Nacional Revolucionario.

${ }^{5}$ Sobre las relaciones entre ciencia y ambiente a través de la prensa mexicana, ver Vega y Ortega (2013: 387-426).

\section{Referencias bibliográficas}

Aguilar Roca, Leopoldo (1936). "Plan general de trabajo de las escuelas federales del Territorio de Quintana Roo, para desarrollar durante el año escolar de 1936-1937". En Periódico Oficial del Gobierno del Territorio de Quintana Roo, l(21): 5-8.

Cárdenas, Lázaro (1936). "Programa de trabajo que desarrollará el Gobierno de la República en los
Territorios Federales de la Baja California y Quintana Roo". En Periódico Oficial del Gobierno del Territorio de Quintana Roo, 1(16): 1-4.

Cárdenas, Lázaro (1939a). “Acuerdo que prohíbe el otorgamiento de permisos para la explotación de chicle en la región de Los Chenes del Estado de Campeche y Territorio de Quintana Roo, publicado en el Diario Oficial de la Federación número 29 del 5 de octubre de 1939". En Periódico Oficial del Gobierno del Territorio de Quintana Roo, 4(22): 2.

Cárdenas, Lázaro (1939b). "Resolución en el expediente de dotación de ejidos al poblado de Chuiquilá, Delegación de Isla Mujeres, Territorio de Quintana Roo, Méx., publicado en el Diario Oficial núm. 7 de mayo de 1939". En Periódico Oficial del Gobierno del Territorio de Quintana Roo, 4(11): 6-8.

Cárdenas, Lázaro (1978). Palabras y documentos públicos de Lázaro Cárdenas, 1928-1940. México: Siglo XXI, pp. 215 222.

Careaga, Lorena (1990). Quintana Roo. Una historia compartida. México: Instituto de Investigaciones Dr. José María Luis Mora.

Cisneros, Nidia (2014). "El proceso de formación de la frontera sur de México". En Dimensión Antropológica, 42: 25-55.

Escobar, Antonio e Israel Sandre (2009). "El agua subsumida en la tierra. La reforma agraria en el cardenismo". En Lourdes Martínez (ed.), Lázaro Cárdenas: modelo y legado, vol. 2. México: INEHRM, pp. 193-227.

Gallini, Stefanía (2004). "Problemas de métodos en la historia ambiental de América Latina". En Anuario IHES, 19: 147-171.

García Ramos, José (1936). "Solicitud de tierras de los vecinos del poblado de Nocbec al gobierno del Territorio". En Periódico Oficial del Gobierno del Territorio de Quintana Roo, 1(11): 3.

González Ramírez, Guillermo (1937). “Cédula notificatoria común a los propietarios de fincas afectables conforme al Código Agrario, situadas en un radio de siete kilómetros del poblado de Kantunilkín, Delegación de Isla Mujeres, Territorio de Quintana Roo". En Periódico Oficial del Gobierno del Territorio de Quintana Roo, 2(28): 4. 
González y González, Luis, (1997). Los artífices del cardenismo. México: El Colegio Nacional/Clío.

Leff, Enrique (2005). "Vetas y vertientes de la historia ambiental latinoamericana. Una nota metodológica y epistemológica". En Varia Historia, 33: 17-31.

Macías, Carlos (2007). "El Caribe mexicano. Historia e historiografía contemporánea”. En Relaciones, 28(111): 67-115.

McNeill, John (2005). "Naturaleza y cultura de la historia ambiental”. En Nómadas, 22: 12-22.

Melgar, Rafael E. (1936a). "Acta de entrega del aserradero a la Cooperativa de "ejidatarios de Chetumal"'. En Periódico Oficial del Gobierno del Territorio de Quintana Roo, 1(1): 1-2.

Melgar, Rafael E. (1936b). "Dotación de tierras al poblado de Nohbec. Resolución”. En Periódico Oficial del Gobierno del Territorio de Quintana Roo, 1(20): 3-4.

Melgar, Rafael E. (1937). "Resolución provisional. Reservación forestal para el poblado de Tulum, Delegación de Cozumel, T. Q. Roo". En Periódico Oficial del Gobierno del Territorio de Quintana Roo, 2(37): 9-10.

Melgar, RafaelE. (1940). “Resolución de ejidos del poblado de Allende — antes Estévez-, Río Hondo, Delegación de Ciudad Chetumal, Territorio de Quintana Roo". En Periódico Oficial del Gobierno del Territorio de Quintana Roo, 5(23): 1.

"Obras que se realizarán en el Territorio de Quintana Roo, en 1937” (1936). En Periódico Oficial del Gobierno del Territorio de Quintana Roo, 1(19): 1.

Pérez Aguilar, Raúl (2014). "El chicle en Quintana Roo: sus caminos y voces”. En Cuicuilco, 60: 1965-222

Rangel, Edgar (2013). "Plantaciones agrícolas-forestales en la costa oriental de Yucatán: explotación forestal, colonización y arrendamiento, 1890-1910". En Asociación Mexicana de Historia Económica (ed.), Segundas Jornadas de Historia de México de la Asociación Mexicana de Historia Económica. México, AMHE, pp. 1-27.

Rangel, Edgar (2014). Compañías deslindadoras y sociedades forestales. Empresariado en el entorno fronterizo de la costa oriental y creación de un borde en las márgenes del Río Hondo, 1876, 1936. Tesis de doctorado en Historia en CIESAS. Mérida, México.
Redacción (1937). "Directorio. Funcionarios públicos del Territorio y de la Federación. Oficinas". En Periódico Oficial del Gobierno del Territorio de Quintana Roo, 2(32): 10.

Redactores (1938a). "Directorio. Funcionarios públicos del Territorio y de la Federación. Oficinas". En Periódico Oficial del Gobierno del Territorio de Quintana Roo, 3(9): 4.

Redactores (1938b). "Lee el Periódico Oficial”. En Periódico Oficial del Gobierno del Territorio de Quintana Roo, 3(11): 4.

Rojas, Alexis (2010). "Reflexión sobre investigación en historia ambiental”. En Revista Reflexiones, LXXXIX(2): 177-190.

Romero, Rafael y Leonardo Rioja (2012). "Frontera en conflicto. El diferendo limítrofe entre los estados peninsulares de Quintana Roo y Campeche, México, en el punto de unión territorial (PUT)”. En Gerard Jori (ed.), Las independencia y construcción de estados nacionales: poder, territorialización y socialización, siglos $X I X-X X$. Barcelona: Geocrítica, pp. 1-16.

Sánchez Tapia, R., Eduardo Suárez y Miguel Ángel de Quevedo (1936). "Bases a que deberá sujetarse en su funcionamiento el Comité creado para la vigilancia, explotación y exportación del chicle, maderas y demás riquezas forestales en los Estados de Veracruz, Campeche, Tabasco, Chiapas y Yucatán y en el Territorio de Quintana Roo". En Periódico Oficial del Gobierno del Territorio de Quintana Roo, 1(13): 1-4.

Valdez-Hernández, Mirna e Islebe, Gerald (2011). "Tipos de vegetación en Quintana Roo”. En Carmen Pozo (ed.), Riqueza biológica de Quintana Roo. Un análisis para su conservación. México: Comisión Nacional para el Conocimiento y Uso de la Biodiversidad/Gobierno del Estado de Quintana Roo, pp. 32-36.

Vázquez Vela, G. (1937). "Concurso de la mejor escuela rural". En Periódico Oficial del Gobierno del Territorio de Quintana Roo, 2(22): 3.

Vega y Ortega, Rodrigo (2013). "Los naturalistas mexicanos y los temas ambientales publicados en $\mathrm{La}$ Naturaleza (1870-1905)". En Celina Lértora (coord.), Territorio, recursos naturales y ambiente: hacia una historia comparada: estudio a través de Argentina, México, Costa Rica, Haití, Paraguay, Uruguay y Venezuela. Buenos Aires: FEPAI, t. I, pp. 387-426. 
Vega y Ortega, Rodrigo (2015). "El devenir de la Exposición Minera Permanente a través del Periódico Oficial del Gobierno del Estado de Chihuahua (1904-1913)". En Luz Fernanda Azuela y Rodrigo Vega y Ortega (coord.), Actores y espacios de la Geografía y la Historia Natural de México, siglos XVIII-XX. México: UNAM, pp. 163-194.

Villalobos, Martha (1993). "Las concesiones forestales en Quintana Roo a fines del porfiriato”. En Relaciones, 53: 87-112.

Villalobos, Martha (2006). El bosque sitiado. Asaltos armados, concesiones forestales y estrategias de resistencia durante la Guerra de Castas. México: CIESAS, INAH, Miguel Ángel Porrúa.
Villarreal, Eduardo (2009). Construcción de la identidad en Quintana Roo. Una visión microhistórica (1902-1974). Tesis de maestría en Ciencias Sociales. Universidad de Quintana Roo, Chetumal, México.

Worster, Donald (2006). Transformaciones de la tierra. Ensayos de historia ambiental. San José: EUNED.

Zepeda, Victoriano (1936a). "Acta de posesión provisional del poblado de Solferino, perteneciente a la Delegación de Islas Mujeres del Territorio de Quintana Roo". En Periódico Oficial del Gobierno del Territorio de Quintana Roo, 1(5): 1-2.

Zepeda, Victoriano (1936b). "Resolución sobre dotación definitiva de tierras al pueblode Kantunilkín, Delegación de Cozumel, Territorio de Quintana Roo". En Periódico Oficial del Gobierno del Territorio de Quintana Roo, 1(6): 3-4. 